Fournal of Medical Genetics (1975). 12, 412-427.

\section{Trisomy of the short arm of chromosome 10}

Summary. A case of a fetus with multiple malformations is described. The mother showed a $46, \mathrm{XX}, \mathrm{rcp}(10 ; 22)$ (p11;p11) karyotype. Amniocentesis at the 16th week of gestation revealed that the male fetus had a der(22) chromosome-that is, he was trisomic for a large part of 10p (10pter $\rightarrow 10 \mathrm{p} 11)$.

Clinical findings of cases with $10 \mathrm{p}$, $10 \mathrm{q}$, and mosaic 10 trisomies are briefly reviewed.

Recently, Nakagome et al (1973) reported a case of mosaic 10 trisomy. In addition, they found two cases of $\mathbf{C}$ trisomy with strikingly similar clinical features reported in the literature. They postulated that the trisomy 10 was a clinical as well as cytogenetic entity. In the present report a case is described of a prenatally diagnosed 10p trisomy due to maternal $\mathrm{rcp}(10 ; 22)(\mathrm{p} 11 ; \mathrm{p} 11)$ translocation. Necropsy findings are also presented.

\section{Case report}

A 30-year-old woman was referred to us for prenatal chromosome analysis. She had previously had a malformed boy and chromosome studies revealed that she, one of her two sisters, and her mother were carriers of a $t(C p-; G p+)$ translocation (Yanagisawa and Adachi, 1970). The boy had a 46,XY, $-G$, + F karyotype-that is he was trisomic for the short arm of a C-group chromosome.

Since then the woman has had two pregnancies; however, both of them were terminated because of her fear of having another malformed baby. Recently, she learned about amniocentesis and elected to have the test.

Amniocentesis in the 16th week of gestation revealed that the fetus had the same unbalanced karyotype as the malformed brother. In the 22nd week of gestation, the pregnancy was terminated. The result of amniotic-

Received 8 July 1974.

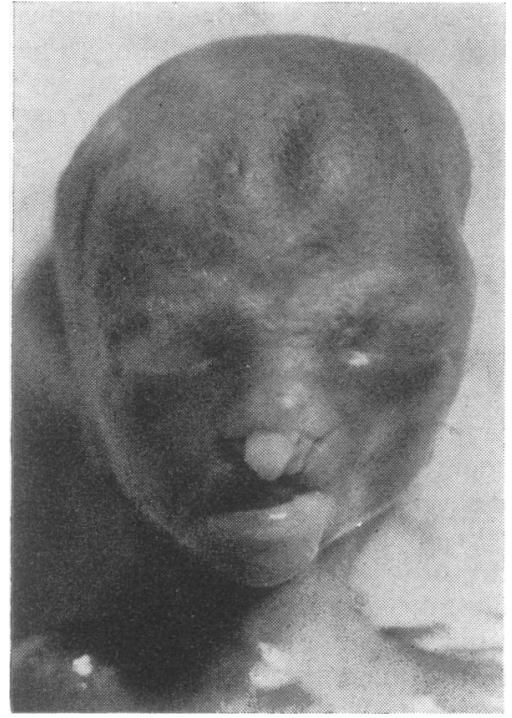

FIG. 1. Appearance of the fetus showing hypertelorism, cleft lip, and micrognathia.

fluid culture was confirmed by cord-blood and skin cultures. The fetus was $345 \mathrm{~g}$ in weight and was grossly malformed (Fig. 1) with hypertelorism, low-set ears, cleft palate, hare-lip, micrognathia, anal atresia, and severe pes varus. Necropsy disclosed a rectovaginal fistula. There were only two lobes instead of three in the right lung. Other necropsy findings were unremarkable. The clinical findings in the present case, as well as those of a case of mosaic 10 trisomy, a 10p trisomy, and two cases of $10 \mathrm{q}$ trisomy, are presented in the Table.

\section{Cytological findings}

A G-banding study revealed that the mother was a balanced carrier of a translocation $\mathrm{rcp}$ $(10 p-; 22 p+)$. The details of the technique used are described elsewhere (Nakagome, 1973). Further, the points of breakage were determined to be within the bands $10 \mathrm{p} 11$ and 22p11 (Fig. 2). The karyotype was designated as $46, \mathrm{XX}, \operatorname{rcp}(10 ; 22)$ (p11;p11). The extra F-group chromosome in amniotic-fluid culture cells was identified as $\operatorname{der}(22)$ of the same translocation-that is, the fetus was a 
TABLE

SUMMARY OF CLINICAL FINDINGS IN CASES WITH 10, 10p, AND 10q TRISOMY

\begin{tabular}{|c|c|c|c|c|c|}
\hline & \multicolumn{5}{|c|}{ References } \\
\hline & $\underset{(1973)}{\text { Nakagome et al }}$ & Present Case & $\begin{array}{l}\text { Yanagisawa and } \\
\text { Adachi (1970) }\end{array}$ & $\underset{(1967)}{\text { Bühler et al }}$ & $\begin{array}{c}\text { Tsuchimoto and } \\
\text { Bühler (1974) }\end{array}$ \\
\hline Karyotype & $+10 /$ normal & $+10 p$ & $+10 p^{*}$ & $+10 \mathrm{qt}$ & $+10 q$ \\
\hline Age & $5 \mathrm{yr}$ & Fetus (22 wk) & $\begin{array}{l}\text { Died at } 101 \\
\text { days of age }\end{array}$ & $10 \mathrm{yr}$ & $\begin{array}{l}\text { Died at } 2 \\
\text { days of age }\end{array}$ \\
\hline Sex & $\mathbf{M}$ & $\mathbf{F}$ & $\mathbf{M}$ & $\mathbf{M}$ & $\mathbf{M}$ \\
\hline Mental retardation & + & $?$ & $?$ & + & $?$ \\
\hline Deformed skull & + & - & - & - & - \\
\hline Strabismus & + & $?$ & - & + & $?$ \\
\hline Hypertelorism & + & + & + & - & - \\
\hline Low-set ears & + & + & + & + & + \\
\hline Malformed ears & + & $-?$ & + & + & - \\
\hline Harelip & - & + & + & - & - \\
\hline Cleft palate & - & + & + & + & + \\
\hline Micrognathia & + & + & - & + & + \\
\hline Agenesis of corpus callosum & + & $?$ & $?$ & - & $?$ \\
\hline $\begin{array}{l}\text { Arthrogryposis or flexion } \\
\text { deformity of fingers and toes }\end{array}$ & + & - & - & + & + \\
\hline Deformed feet & + & + & + & - & - \\
\hline Abnormal genitalia & - & + & + & - & - \\
\hline
\end{tabular}

* Originally reported as partial $\mathbf{C}$ trisomy (see text).

+ Originally reported as trisomy $12 q$ (see text).

tertiary trisomy for a large part of the short arm of a No. 10 chromosome (10pter $\rightarrow 10 \mathrm{p} 11)$. A very small part of the short arm and the satellite of a No. 22 were missing.

\section{Discussion}

As far as the authors are aware, there has been only one reported case of trisomy 10 in which the extra chromosome was identified by banding studies (Nakagome et al, 1973). In 1967 Bühler et al

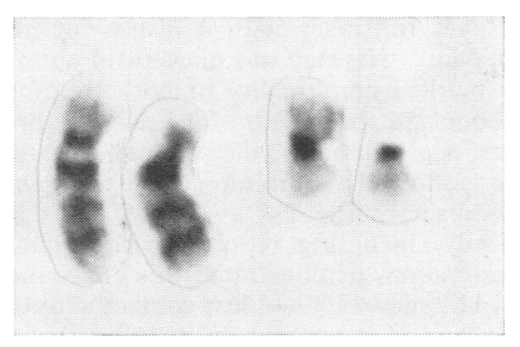

Fig. 2. Partial karyotype showing chromosomes Nos. 10 and 22 of the mother. Break points were within bands 10p11 and 22p11. described a case of 'partial trisomy 12'. Recently, Tsuchimoto and Bühler (1974, personal communication) re-examined the case using banding techniques and found that the case was, in fact, trisomic for the distal part of 10q. They also described an unrelated case of a 10q trisomy. The only reported case of $10 p$ trisomy was the brother of the present case (Yanagisawa and Adachi, 1970).

The case with trisomy of a whole No. 10 chromosome seemed to have more malformations (Table). A few malformations, such as harelip, cleft palate, and abnormal genitalia, were not observed in this case although they were found in cases of $10 \mathrm{p}$ and/or $10 \mathrm{q}$ trisomy. Either phenotypic variation or the presence of mosaicism could account for this. A few malformations observed in cases of $10 p$ trisomy were not present in $10 \mathrm{q}$ trisomy (and vice versa). There seem to be some differences in phenotype between these two partial trisomies.

The trisomy 10 was postulated to be a clinical as well as cytogenetic entity (Nakagome et al, 1973). It may be too early to decide whether both $10 \mathrm{p}$ and $10 \mathrm{q}$ trisomy correspond to independent clinical entities. However, the phenotypic difference observed between these two conditions suggest that 
this may be so. In any event, further reports of cases with these chromosome abnormalities will be of great importance in establishing these two possible new syndromes.

The authors wish to express their thanks to $\mathrm{Dr}$ Yanagisawa, Department of Paediatrics, Yamaguchi University School of Medicine, for information on the family. Thanks are also due to Dr Matsui, Kanagawa Children's Medical Center, for cord-blood culture. This study was aided in part by a grant from the Ministry of Health and Welfare.

Yasuo Nakagome and Hideo Kobayashi Department of Human Genetics, National Institute of Genetics, Mishima and Department of Obstetrics and Gynecology, Kawasaki City Hospital, Kawasaki, fapan

\section{REFERENCES}

Bühler, U. K., Bühler, E. M., Sartorius, J., and Stalder, G. R. (1967). Multiple Missbildungen bei partieller Trisomie C(12) als Manifestation einer erblichen E/C (18/12) Translokation. Helvetica Paediatrica Acta, 22, 41-53.

Nakagome, Y. (1973). G-group chromosomes in satellite associations. Cytogenetics and Cell Genetics, 12, 336-341.

Nakagome, Y., Iinuma, K., and Matsui, I. (1973). Trisomy 10 with mosaicism. A clinical and cytogenetic entity. fapanese Fournal of Human Genetics, 18, 216-219.

Yanagisawa, S. and Adachi, K. (1970). A case of multiple congenital anomalies with familial $\mathrm{C} / \mathrm{G}$ translocation. fapanese fournal of Human Genetics, 14, 309-315.

\section{Stub thumbs}

\author{
Summary. A case of familial brachy- \\ dactyly is reported.
}

Bell (1951) and Temtamy and McKusick (1969) have classified the different types of brachydactyly due to maldevelopment of the phalanges or metacarpals. It may occur as an isolated phenomenon or as part of a syndrome. Type D brachydactyly or 'stub thumbs' is characterized by shortening and broadening of the terminal phalanges of the thumb and big toes. It is usually an isolated finding but has been reported in association with cardiac arrhythmias (Tabaznick, 1965).

Received 22 July 1974.

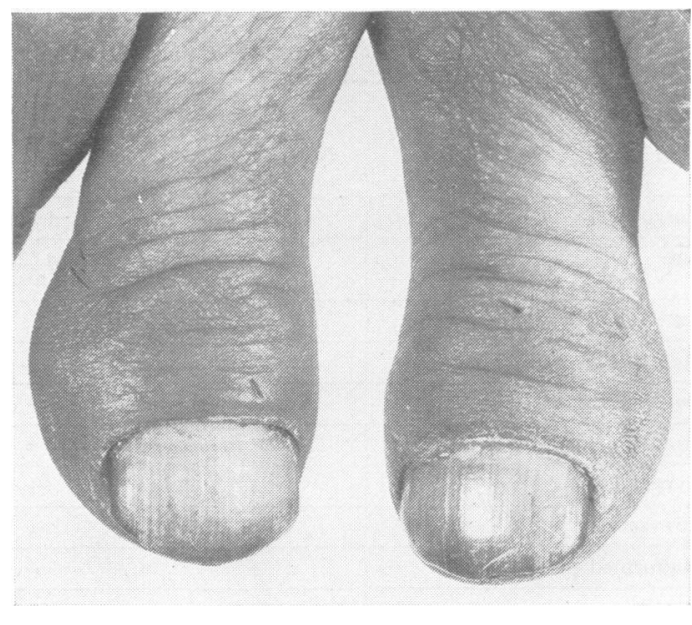

Fig. 1. Stub thumbs in the propositus.

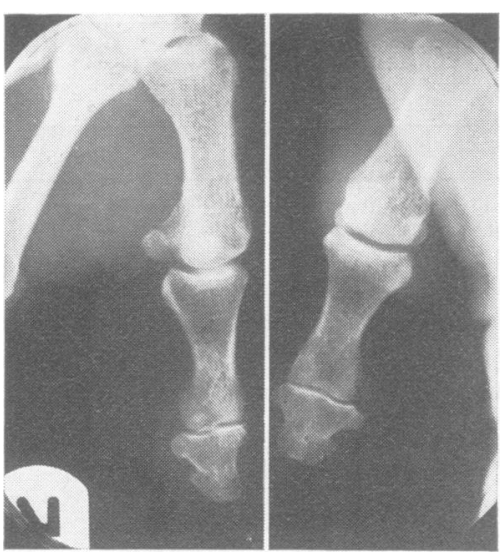

FIG. 2. Radiograph showing shortening of the terminal phalanx in the propositus.

\section{Case report}

A 49-year-old manual worker was admitted to the Cardiff Royal Infirmary with a history of myocardial ischaemic pain. His stay was uneventful but he demonstrated a marked abnormality of both thumbs. They were bulbous and shortened. The nail was broad (Fig. 1). There was no abnormality of his toes. Radiology of the hands showed a shortening of the terminal phalanx in the thumbs only (Fig. 2).

His family, including reportedly the whole of the second generation, demonstrated this abnormality (Fig. 3). II.1, II.2, and II.3 had lost contact with the rest of the family and it is not known whether their progeny were affected. There were no other congenital abnormalities noted in the family. 